\title{
SCIDOC
}

\author{
International Journal of Dentistry and Oral Science (IJDOS) \\ ISSN: 2377-8075
}

\section{Factors Influencing differences between Patient's Self-Perceived Oral Care Needs and Clinical Findings in a Nigerian Population}

Research Article

Dosumu $\mathrm{EB}^{1 *}$, Onigbinde $\mathrm{OO}^{2}$, Ogunsuji $\mathrm{OO}^{3}$

${ }^{1}$ Faculty of Dentistry, Department of Periodontology \& Community Dentistry, College of Medicine, University of Ibadan, Ibadan, Nigeria.

${ }^{2}$ Faculty of Dentistry, Department of Preventive Dentistry, Lagos State University, Lagos, Nigeria.

${ }^{3}$ Department of Periodontology \& Community Dentistry, University College Hospital, Ibadan, Nigeria.

\section{Abstract}

Statement of Problem: There is a gap in the knowledge of self-perception of patients about their oral health status and the clinical findings.

Aim: To evaluate the factors that influence the correctness of oral health self-perception when related with real clinical findings in this environment.

Method: Two hundred and thirteen consecutive adult patients attending the Dental Centre of the University College Hospital, Ibadan, Nigeria were recruited into this study. Evaluation of their intraoral status was done with self and interviewer based questionnaire and clinical assessment for teeth caries and gum inflammation status done using the DMFT (Decayed, Missing and Filled Teeth) Index and the OHI-S (Oral Hygiene Index Simplified) by Green and Vermillion respectively. Informed consent was obtained from all the participants before recruiting them into the study and institutional ethical approval was also obtained. All clinical examinations were done in standard dental clinic setting and adequate illumination. Data was analyzed using simple frequency and distribution, Mann-Whitney $U$ test and the one way ANOVA with Tukey HSD post-hoc test for the bi-variant analysis to test for significant difference between the variables.

Result: The OHI-S assumed an almost normal distribution across the participants with a mean of $2.6188( \pm 1.413)$ and skewness of 0.509 while the DMFT doesn't, with mean of 2.148 ( \pm 2.843$)$ and skewness of 2.25. A one way ANOVA with Tukey HSD post-hoc test showed educational level, marital status and gender to be statistically significant $(\mathrm{p}<0.05)$ for mean OHI-S with only gender and educational level being the only significant predictors using multiple linear regression analysis. Mann-Whitney $\mathrm{U}$ test showed a statistically significant difference $(\mathrm{p}<0.01)$ between the mean DMFT for marital status and educational levels.

Conclusion: Gender, educational levels and marital status are significant factors that influence the correctness of oral health self-perception when related with clinical findings with only gender and educational status as the only significant predictors for periodontal disease.

Abbreviations: DMFT: Decayed Missing Filled Teeth; CPITN: Community Periodontal Index of Treatment Need; OHI-S: Oral Hygiene Index Simplified; TMJ: Temporomandibular Joint.

\section{Introduction}

Caries and periodontal diseases are the two foremost reported oral pathologies and their clinical assessment is expensive, invasive, uncomfortable, and complicated by medico-legal and ethical obstacles [1-6]. One important component in the use of service is the self-perceived need [7] and self-perception influences service use. The perceived oral health is a subjective measure of an individual's perception of his or her health [8]. The self-perceived oral health of an individual is determined by the clinical oral conditions and the impact of oral health on daily life [9].

Access to health education may also be influenced by self-per-

\footnotetext{
*Corresponding Author:

Elizabeth Bosede Dosumu,

Faculty of Dentistry, College of Medicine, Department of Periodontology \& Community Dentistry, University of Ibadan, Nigeria.

Tel: 08034086922

Fax: +234

E-mail: edosumu18jj@mail.com

Received: February 12, 2019

Accepted: March 08, 2019
}

Published: March 09, 2019

Citation: Dosumu EB, Onigbinde OO, Ogunsuji OO. Factors Influencing differences between Patient's Self-Perceived Oral Care Needs and Clinical Findings in a Nigerian Population. Int J Dentistry Oral Sci. 2019;6(3):685-690. doi: http://dx.doi.org/10.19070/2377-8075-190000135

Copyright: Dosumu $\mathbf{E B}^{\circ}$ 2019. This is an open-access article distributed under the terms of the Creative Commons Attribution License, which permits unrestricted use, distribution and reproduction in any medium, provided the original author and source are credited. 
ceptions of health conditions [7]. Individuals usually give greater importance to the symptoms and the functional and psychological impact of the disease than to the invisible signs of the disease $[7,10]$. Dental patient's perception is an important factor in the diagnosis and eventual successful management of the dental ailments by the dental professional [5]. Self-perception levels of oral health were reported to be higher than that of the clinical findings of the diseases by some researchers [4]. This was also reported to reflect a low level of the public which may influence care seeking behavior which also highlights the importance of oral health promotion with the crucial need for public health actions [4].

Comparisons of oral health normative versus efficacy of selfperception of the individual to evaluate personal health status assessment are reported to either be precise or not precise [11]. Self-Perceived assessment data have neither been found as useful nor successful in the assessment of individual dental and periodontal health status [11-13]. Azodo et al., [14] recommended the need for periodic oral health education among a group of dental auxiliary students in order to improve the utilization of the existing dental services and eventual improvement of self-perceived oral health.

Following the reported importance of self-perceived oral care need, this study therefore aimed to determine the factors that influence self-perceived oral care need and subsequent longevity of the teeth.

\section{Materials and Methods}

Two hundred and thirteen consecutive adult patients aged 18 to 65 years attending the Dental Centre of the University College Hospital, Ibadan, Nigeria were evaluated by means of self and interviewer based questionnaires and intraoral clinical examinations. The questionnaire was about their socio-demography and their opinions about the health status of their teeth and gums. The clinical examination included assessment of their caries status using the DMFT (Decayed Missing Filled Teeth) index and periodontal status using the CPITN (Community Periodontal Index of Treatment Need) and the OHI-S(Oral Hygiene Index Simplified) by Green and Vermillion. Informed consent was obtained from them before recruiting them into the study and institutional ethical approval was also obtained. All clinical examinations were done in standard dental clinic setting and adequate illumination.

Inclusion criteria were patients who consented to participate after full explanation of the study; in good health, not on any routine medication and coherent. The exclusion criteria were patients with underlying systemic conditions that may affect the oral tissues such as Diabetes Mellitus that might affect the periodontal status of the patient.

\section{Questionnaire used in the assessments}

1. Age as at last birthday

2. Sex

Male

Female

3. Marital status a) Married b) Single c) Divorced d) Separated

4. Highest level of education a) Primary b) Secondary c) Tertiary d) Postgraduate e)None

5. Occupation

6. Ethnic group a) Yoruba b) Hausa c) Igbo d) Others

7. What is your opinion regarding the health status of your gum and teeth? a) Very poor b) Poor c) Not so good d) Good

e) Very good f) Excellent

8. What is your opinion regarding the health status of your gum? a) Very poor b) Poor c) Not so good d) Good e) Very good f) Excellent .

9. What type of teeth/gum problem do you think you have? (Please thick as many as it applies to you) a) Hole in the teeth b) Food packing between the teeth c) Sensitive teeth d) Bleeding gums e) Swollen gums f) Tartar on the teeth g) Mal-aligned teeth

10. Teeth present

11. Mal-aligned teeth

12. DMFT index

13. CPITN index

14. OHI-S index (Greene and Vermillion) 
Data was analyzed using simple frequency and distribution, the one way ANOVA with Tukey HSD post-hoc test and the MannWhitney $U$ test bi-variant and multi-variant to test for levels of significance of the variables.

\section{Result}

There was an almost equal distribution of gender, $52.4 \%$ females and $47.6 \%$ males. $57.3 \%$ of the respondents had tertiary education while only $5.6 \%$ had no formal education. $56.1 \%$ of the respondents were either married, $39.9 \%$ were single and majority
$(76.5 \%)$ of the respondents were of the Yoruba ethnicity (Table $1)$.

The OHI-S assumed an almost normal distribution across the participants with a mean of $2.6188( \pm 1.413)$ and skewness of 0.509 as compared to the DMFT which doesn't appear to follow a normal distribution with mean of $2.148( \pm 2.843)$ and skewness of 2.25 (Table 2).

Statistically significant difference was observed between mean OHI-S of males and females $(\mathrm{p}<0.05)$, singles and married $(\mathrm{p}<0.01)$ with both males and married participants having higher

Figure 1. Percentage of the Respondents Reporting Various Oral Health Problems.

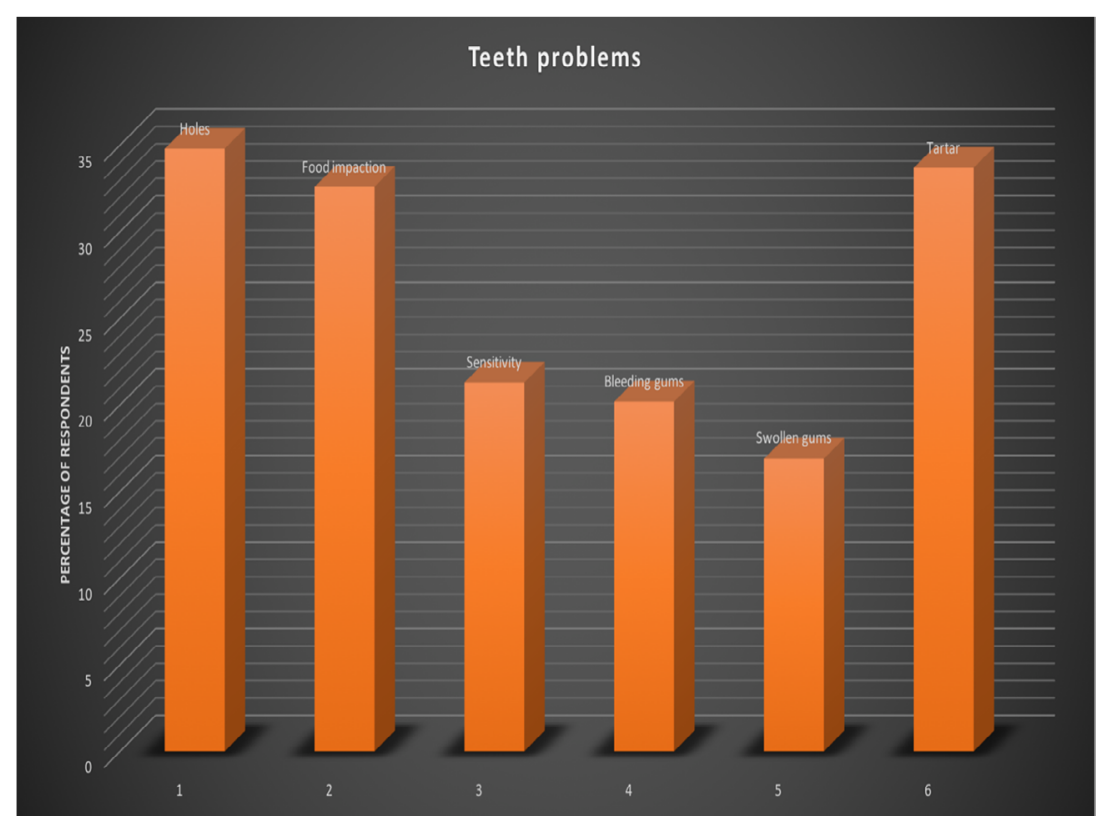

Table 1. Socio-demography of Participants.

\begin{tabular}{|c|c|c|}
\hline \multirow{2}{*}{\multicolumn{2}{|c|}{ Age }} & Mean (SD) \\
\hline & & $41.4 \pm 18.46$ \\
\hline & & $\mathbf{N}(\%)$ \\
\hline \multirow{2}{*}{ Gender } & Males & $98(47.6)$ \\
\hline & Females & $108(52.4)$ \\
\hline \multirow{5}{*}{ Education } & None & $12(5.6)$ \\
\hline & Primary & $17(8.0)$ \\
\hline & Secondary & $45(21.1)$ \\
\hline & Tertiary & $122(57.3)$ \\
\hline & Postgraduate & $17(8)$ \\
\hline \multirow{4}{*}{ Marital status } & Single & $79(39.9)$ \\
\hline & Married & $111(56.1)$ \\
\hline & Divorced & $1(0.5)$ \\
\hline & Widow & $7(3.5)$ \\
\hline \multirow{5}{*}{ Ethnicity } & Yoruba & $163(76.5)$ \\
\hline & Igbo & $14(6.6)$ \\
\hline & Hausa & $2(0.9)$ \\
\hline & Edo & $12(5.6)$ \\
\hline & Others & $22(10.4)$ \\
\hline
\end{tabular}

$(\mathrm{N}=213)$ 
mean OHI-S respectively.

A one way ANOVA with Tukey HSD post-hoc test reveals a significant statistical difference $(\mathrm{p}<0.05)$ between the mean OHI-S of participants who hadn't gone beyond primary education and those that had at least tertiary education, with those who had at least tertiary education having a lower mean OHI-S (Table 3).

Mann-Whitney $U$ test shows a statistically significant difference $(p<0.01)$ between the mean ranks DMFT of single and married participants with married participants showing a higher mean DMFT 2.540 (Table 4).

There was also a statistically significant difference between the mean DMFT of participants with primary education and secondary education while participants with primary school education had a higher mean DMFT of 3.1724 .

Using the multivariate analysis the independent variables were fixed into a model to predict the dependent variable OHI-S using a multiple linear regression. The independent variables accounted for only $5.6 \%$ of the changes in the OHI-S with only gender and education being significant predictors of the OHI-S (Table 5).

\section{Discussion}

OHI-S is one of the indices that is used to quantitatively assess oral cleanliness and periodontal health while DMFT assesses the caries experience of the individual. Both the periodontal status and caries experience form part of the oral health status of an individual.

Self-perceived oral health was reported to have a bi-directional change in deterioration and improvement in older adults in Brazil [12]. Manuela et al., [13] in their study on the elderly reported gender, age, individual's educational status, access to dental services and oral health education as factors that influence oral health selfperception. Knowledge among young people about oral health and practices and the etiology of oral diseases are influencing factors in their self-perception of oral diseases [15]. Age was not found to influence the self-perception of oral health in our study subjects which is contrary to these other studies $[12,13,15]$. This

Table 2. The OHI-S and DMFT distribution across the participants.

\begin{tabular}{|c|c|c|c|c|}
\hline & Mean & SD & Skewness & Range \\
\hline OHI-S & 2.619 & 1.413 & 0.509 & 6 \\
\hline DMFT & 2.141 & 2.843 & 2.25 & 19 \\
\hline
\end{tabular}

Table 3. Bivariate Analysis of OHI-S with Gender, Marital status and Educational level.

\begin{tabular}{|c|c|c|c|c|}
\hline & & Mean OHI-S & $\mathbf{t}(\mathbf{d f})$ & P value \\
\hline \multirow{3}{*}{ Gender } & Females & 2.389 & $-2.139(200)$ & 0.034 \\
\cline { 2 - 5 } & Males & 2.813 & & \\
\hline \multirow{3}{*}{ Marital status } & Single & 2.325 & $-2.824(184)$ & 0.005 \\
\cline { 2 - 5 } & Married & 2.897 & & \\
\hline & & & $\mathrm{F}(\mathrm{df})$ & \\
\hline \multirow{3}{*}{ Education } & None + Primary & 3.220 & $3.029(2 ; 206)$ & 0.051 \\
\cline { 2 - 6 } & Secondary & 2.580 & & \\
\cline { 2 - 6 } & Tertiary+ PG & 2.509 & & $* 0.040$ \\
\hline
\end{tabular}

*Post-hoc test(Tukey HSD) shows statistical significant difference between OHI-S of (None+ Primary) and (Tertiary+Postgraduate (PG)).

Table 4. DMFT Related to Gender, Marital status and Educational level.

\begin{tabular}{|c|c|c|c|}
\hline & & Mean DMFT & P value \\
\hline \multirow{3}{*}{ Gender } & Females & 2.3571 & 0.617 \\
\cline { 2 - 4 } & Males & 2.0000 & \\
\hline \multirow{3}{*}{ Marital status } & Single & 1.3924 & 0.005 \\
\cline { 2 - 4 } & Married & 2.5405 & \\
\hline \multirow{3}{*}{ Education } & None + Primary & 3.1724 & 0.028 \\
\cline { 2 - 4 } & Secondary & 1.4889 & \\
\cline { 2 - 4 } & Tertiary+ PG & 2.1367 & $* 0.008$ \\
\hline
\end{tabular}

*Post-hoc test with Bonferroni correction shows statistical significant difference between the DMFT ranks of secondary and (none + primary). 
Table 5. Multivariate analysis: Multiple linear regression(Dependent variable is OHI-Simplified).

\begin{tabular}{|c|c|c|c|c|}
\hline & $\mathbf{b}$ & $\mathbf{S E}(\mathbf{b})$ & Sig & $\mathbf{9 5 \%}$ CI \\
\hline Constant & 3.446 & 0.592 & 0 & 2.278 to 4.614 \\
\hline $\begin{array}{c}\text { Sex } \\
\text { Ref (Males) }\end{array}$ & 0.461 & 0.2 & $0.022^{*}$ & 0.066 to 0.815 \\
\hline $\begin{array}{c}\text { Marital status } \\
\text { Ref (Married) }\end{array}$ & -0.195 & 0.495 & 0.694 & -1.171 to 0.781 \\
\hline $\begin{array}{c}\text { Education } \\
\text { Ref (None+Primary) }\end{array}$ & -0.339 & 0.142 & $0.018^{*}$ & -0.619 to -0.060 \\
\hline
\end{tabular}

$\mathrm{R}^{2}=0.056$, Adjusted $\mathrm{R}^{2}=0.041$

may be because our study included only adult patients but not the young adults and the elderly.

Hernández-Palacios et al., [16] reported gender(male), low income and low educational level and poor oral health to be associated with poor self-perceived oral health in elderly Mexicans. We found gender to be a common significant influencing factor for oral health self-perception with both OHI-S and DMFT in our study subjects which is in keeping with findings of HernándezPalacios et al., [16]. We had an almost equal distribution of gender, $52.4 \%$ females and $47.6 \%$ males in this study which may explain the significant influence of gender on oral health self-perception that we are reporting.

Oral health education and socio-economic status were found to influence oral health self-perception in pregnant women [17]. Psychosocial factors, utilization of oral care services, adherence to oral health recommendations and practice of good oral health were found to influence the oral health perception of pregnant women [18]. Another study [19] found a low level of health perception compared to the clinical findings influenced by public awareness and their eventual care-seeking behavior. In this study, we found marital status and level of education of the participants to significantly influence their oral health self-perception which might have been influenced by their socio-economic factors, utilization of oral care services, adherence to oral health care recommendations, oral health education and awareness. This may therefore be in keeping with these previous studies [17-19].

Pinelli et al., [20] in their study found self-perceived oral health to be reliable for periodontal, dental, and temporomandibular joint (TMJ) conditions while validity was found to be more sensitive to detect the presence of periodontal disease. Non-oral and some extrinsic factors such as smoking were reported to influence the self-perception of patients about halitosis [8]. Another reported influencing factor in the self-perception of oral health is the intensity of the disease [9]. We found gender and educational level of the participants to be significant predictors of influencing factors for self-perception of periodontal diseases probably because detecting periodontal disease is easier even in the early stage with obvious symptoms of bleeding gums. This our finding is in keeping with some of these previous studies $[8,9,20]$.

\section{Conclusion}

Within the limits of this study being the study size, age group and limited number of influencing factors analyzed, we report that gender, educational levels and marital status significantly influence oral health self-perception of individuals with only gender and educational status as the only significant predictors for periodontal disease.

\section{References}

[1]. Barmes DE. A global view of oral diseases: today and tomorrow. Community Dent Oral Epidemiol. 1999 Feb;27(1):2-7. PubMed PMID: 10086920.

[2]. Abu Alhaija ES, Al-Nimri KS, Al-Khateeb SN. Self-perception of malocclusion among north Jordanian school children. Eur J Orthod. 2005 Jun;27(3):292-5. PubMed PMID: 15947230.

[3]. Ekanayake L, Perera I. Perceived need for dental care among dentate older individuals in Sri Lanka. Spec Care Dentist. 2005 Jul-Aug;25(4):199-205. PubMed PMID: 16295225.

[4]. Gilbert AD, Nuttall NM. Self-reporting of periodontal health status. Br Dent J. 1999 Mar 13;186(5):241-4. PubMed PMID: 10205972.

[5]. Gururatana O, Baker SR, Robinson PG. Determinants of children's oralhealth-related quality of life over time. Community Dent Oral Epidemiol. 2014 Jun;42(3):206-15. PubMed PMID: 24949513.

[6]. Heft MW, Gilbert GH, Shelton BJ, Duncan RP. Relationship of dental status, sociodemographic status, and oral symptoms to perceived need for dental care. Community Dent Oral Epidemiol. 2003 Oct;31(5):351-60. PubMed PMID: 14667006.

[7]. Kelly SE, Binkley CJ, Neace WP, Gale BS. Barriers to care-seeking for children's oral health among low-income caregivers. Am J Public Health. 2005 Aug;95(8):1345-51. PubMed PMID: 16043666.

[8]. Alzoubi FQ, Karasneh JA, Daamseh NM. Relationship of psychological and oral health statuses with self-perceived halitosis in a Jordanian population: a cross-sectional study. BMC Oral Health. 2015 Jul 31;15:89. doi: 10.1186/ s12903-015-0078-7. PubMed PMID: 26227389.

[9]. Javed F, Ahmed HB, Mehmood A, Mikami T, Malmstrom H, Romanos GE. Self-perceived oral health and periodontal parameters in chronic periodontitis patients with and without rheumatoid arthritis. J Investig Clin Dent. 2016 Feb;7(1):53-8. doi: 10.1111/jicd.12113. PubMed PMID: 25044486.

[10]. Levy SM, Warren JJ, Jakobsen JR. Follow-up study of dental students' esthetic perceptions of mild dental fluorosis. Community Dent Oral Epidemiol. 2002 Feb;30(1):24-8. PubMed PMID: 11918572.

[11]. Bedos C, Levine A, Brodeur JM. How people on social assistance perceive, experience, and improve oral health. J Dent Res. 2009 Jul;88(7):653-7. doi: 10.1177/0022034509339300. PubMed PMID: 19641153.

[12]. de Andrade FB, Lebrão ML, Santos JL, de Oliveira Duarte YA. Relationship between oral health and frailty in community-dwelling elderly individuals in Brazil. J Am Geriatr Soc. 2013 May;61(5):809-14. doi: 10.1111/jgs.12221. PubMed PMID: 23647172.

[13]. Nogueira CM, Falcão LM, Nuto SD, Saintrain MV, Vieira-Meyer AP. Selfperceived oral health among the elderly: a household-based study. Rev Bras Geriatr Gerontol, Rio Janeiro. 2017 Feb;20(1):7-19.

[14]. Azodo C, Ehizele A, Umoh A, Ojehanon P, Akhionbare O, Okechukwu $\mathrm{R}$, et al. Perceived oral health status and treatment needs of dental auxiliaries. Libyan J Med. 2010 Mar 15;5. doi: 10.3402/ljm.v5i0.4859. PubMed PMID: 21483589.

[15]. Mehta SP, Bapatla S, Pathak T, Verma J, Thakkar V, Iyer J. Self-Perceived Halitosis amongst School, Junior College and Dental College Students in Navi Mumbai Region-'a Kap Survey'. J Dent Treat Oral Care. 2017 Nov 6;2(1).

[16]. Hernández-Palacios RD, Ramírez-Amador V, Jarillo-Soto EC, Irigoyen- 
Camacho ME, Mendoza-Núńez VM. Relationship between gender, income and education and self-perceived oral health among elderly Mexicans. An exploratory study. Cien Saude Colet. 2015 Apr;20(4):997-1004. doi: 10.1590/1413-81232015204.00702014. PubMed PMID: 25923612.

[17]. Hosseintalaei M, Shahnazi H, Mohammadi M. The relationship of perceived susceptibility and self-efficacy with the decayed, missing, and filled teeth in pregnant women: A study based on the health belief model. Biomed Res. 2017 Jan 1:28(18):8142-8

[18]. Jessani A, Laronde D, Mathu-Muju K, Brondani MA. Self-perceived oral health and use of dental services by pregnant women in surrey, British Co- lumbia. J Can Dent Assoc. 2016 Dec;82:g28. PubMed PMID: 28240578.

[19]. Vered Y, Sgan-Cohen HD. Self-perceived and clinically diagnosed dental and periodontal health status among young adults and their implications for epidemiological surveys. BMC Oral Health. 2003 Jul 13;3(1):3. PubMed PMID: 12857357.

[20]. Pinelli C, Loffredo LD. Reproducibility and validity of self-perceived oral health conditions. Clin Oral Investig. 2007 Dec;11(4):431-7. PubMed PMID: 17610092 